\title{
The Ethics of Care: Normative Structures and Empirical Implications
}

\author{
Tove Pettersen
}

Published online: 5 January 2011

(C) The Author(s) 2010. This article is published with open access at Springerlink.com

\begin{abstract}
In this article I argue that the ethics of care provides us with a novel reading of human relations, and therefore makes possible a fresh approach to several empirical challenges. In order to explore this connection, I discuss some specific normative features of the ethics of care-primarily the comprehension of the moral agent and the concept of care - as these two key elements contribute substantially to a new ethical outlook. Subsequently, I argue that the relational and reciprocal mode of thinking with regard to the moral agent must be extended to our understanding of care. I term this comprehension "mature care". Citing conflicts of interests as examples, I demonstrate how this conceptualization of care may further advance the ethics of care's ability to take on empirical challenges. Finally, I discuss political implications that may emanate from the ethics of care and the concept of mature care.
\end{abstract}

Keywords The ethics of care - Care epistemology · Conflicts · Mature care . Relational ontology · Moral philosophy

\section{Introduction and Purpose}

Twenty-five years ago, care reasoning was associated with decisions made by women in the private sphere regarding their personal dilemmas. Over the last two decades, however, proponents have demonstrated the ideal of care to be capable of guiding not only private conduct, but human interaction in general. Today, thoughts about care have coalesced into an ethical theory with the power to change the way we evaluate personal relationships, professional conduct, public policy, international relations and

T. Pettersen $(\bowtie)$

Department of Philosophy, Classics, History of Art and Ideas, Faculty of Humanities,

University of Oslo, P.O. Box 1020, Blindern, 0315 Oslo, Norway

e-mail: tove.pettersen@ifikk.uio.no 
global issues. Compared with the history of other ethical theories, such as deontology and utilitarianism which have been refined for centuries, this is an extraordinary development. What explains the exponential growth of the ethics of care as a philosophy with relevance for ever wider areas of life, some of which are marked by incompatibilities and opposing interest? One reason is the fecundity of thought among care philosophers who have advanced ethical conceptions, models and methods able to grasp and analyze human relations in all their variety.

When the ethics of care provides us with a novel reading of human relations, a fresh approach to several empirical challenges is possible. A new approach is possible because theorizing on care engenders a radically different set of models and normative concepts than those available under the terms of the conventional ethics and moral philosophy. In order to explore and explain this connection, I shall focus on some specific normative features of the ethics of care, in particular the comprehension of the moral agent and the concept of care, as these key elements contribute substantially to a new outlook. Subsequently, I will argue that the relational and reciprocal mode of thinking with regard to the moral agent must be included within our idea of care. I term such a comprehension "mature care". I then demonstrate how a conceptualization of care as a relational activity advances the ethics of care's ability to take on empirical challenges, using conflicts of interests as examples. Finally, I discuss political implications that may emanate from the ethics of care and the concept of mature care.

\section{The Relational Ontology}

One characteristic feature of the ethics of care, and also a reason for its swift growth and applicability, is its relational ontology. The ethics of care depicts the moral agent not primarily in terms of independence, equality of power and influence, enjoying almost unrestricted freedom to enter and dissolve contracts. Rather, it conceives agents as mutually interconnected, vulnerable and dependent, often in asymmetric ways. This approach lets us visualize the moral agent as a "motherchild-dyad", for example, instead of the "autonomous-man-model", coined by among others Sarah Ruddich [27] and Virginia Held [11]. The conception's transformation took place within the sub-discipline of meta-ethics, but its implications have spread much further afield. What makes this particular model of the moral agent useful as a wider behavioral metaphor for ethicists is its capacity to capture significant features of man's interaction in general, such as reciprocity, dependency, connectedness and asymmetry. These features are present, to various degrees, in all types of relationships and interaction, not only in what we call intimate relationships. And while this conceptualization does indeed have room for important features of intimate and private relationships, easily overlooked by the "autonomous-man-model", it extends to moral agents outside the private domainat work, and in the social and global arena as demonstrated by among others Joan Tronto [30] and Virginia Held [11-13]. For instance, instead of depicting nations as sovereign, self-sufficient and equal in strength, one can envisaging them as relational, mutually dependent, but often unequal in power and resources. 
The relational model allows also for a wider understanding of who the moral agents are: they are not only individuals but also groups, institutions and nations. Consequently, it manages to capture interaction between groups, as well as interaction between groups, institutions and individuals. Relationships transcend boundaries separating the private from the public, the individual from the collective. These "inter-category" relations differ, sometimes quite significantly, from relations within categories, such as between friends, independent citizens or equally powerful states. These mixed relations are embedded in everyday life, and are frequently weighted in favor of one side. Involvement is often involuntary and sometimes coerced; access to power and resources is uneven, as is vulnerability to abuse. In asymmetric relationships, the dominant figure may have almost total power over the other's life and prospects. ${ }^{1}$

People's relationships extend in all directions. Some will engender care, others will stifle its growth and give way to conflict, abuse and violence. Care ethicists should therefore study all kinds of relationships, not only private and professional. As the ethics of care accentuates different features than other theories, e.g., harm caused by lack of care, the agents' vulnerability and dependency, and how they are situated in particular power- and resource situations, it also identifies certain ethical challenges other theories tend to neglect. For instance, the ethics of care is as a result of its focus on interactions, alert to structural violence, i.e. to injuries caused by the way society is organized. ${ }^{2}$ Structural violence infects relationships between institutions and individuals, and is characterized precisely by lack of care between unequal parties, such as the global corporation vis-à-vis the individual. Such harm can be inflicted slowly and might not be immediately apparent. It can take place even if rights are not violated, and the overall good is maximized. When the dominant party (which might be a global corporation or a health authority) forces the less empowered party (who might be a child or health worker) to acquiesce to or subject themselves (or others) to harmful schemes, the relationship counts as abusive. Disempowerment can cause conflict-at the level of the individual and family as well as of the state.

The political scientist and care ethicist Fiona Robinson's discussion on corporate social responsibility is an example of how to understand care and responsibility in such asymmetric "intercategory" relations [26]. Corporate social responsibility is the transnational corporate partnerships' responsibility to assume accountability for the social and natural environment they operate in, and for their economic and social impact. Robinson demonstrates how the ethics of care, with its contextualized focus, can capture certain types of harm more easily than other theories, and how moral arguments springing from the ethics of care can be used against structural violence. Hence, a different normative approach, could pave the way for a more caring environment.

\footnotetext{
${ }^{1}$ In their asymmetrical character, they share some of the features of other unequal relationships: parent and child, nurse and patient, teacher and student, to mention a few.

2 By "structural violence" I refer to what the Norwegian founder of the discipline of peace and conflict studies Johan Galtung [6] calls structural violence: For instance, if a system of government deprives the public of basic necessities and rights like health-care, work, freedom of religion etc., it is guilty of structural violence.
} 


\section{The Normative Heart of Care}

With the model of the moral agent as related, care ethicists become analytically equipped to address a wide variety of relationships and the type of harm some may inflict. ${ }^{3}$ This capacity does not spring from the moral agent being granted a different, more nuanced, compassionate, or a more developed sense of moral imagination than others. The reasons are that the carer applies a different set of analytical concepts and categories than, say, a deontologist or a utilitarian, and what is considered ethical relevant within the ethics of care is not identical with what is given relevance in other theories. What is taken to be of ethical relevance will, in turn, influence the agents' moral perceptions of how ethical challenges are perceived, evaluated and acted on. Hence, different ethical theories will not necessarily view like situations identically — some features are highlighted, some downplayed, while still others are overlooked. The normative theories" emphasis on different features is explained by their separate core values, their moral ontology and their moral epistemology.

The normative core value of the ethics of care is, as I see it, two folded: The universal condemnation of exploit and hurt [7, p. 74, 166, 174], and the universal commitment to human flourishing [7, p. 174, 8, p. 157]. The first commitment shares resemblances with the principle of non-maleficence, and the second with the principle of beneficence. Still, there are some important differences between these two normative principles and care. Commonly, the principle of non-maleficence is understood as refraining from inflicting harm on others, while the normative ideal of care involves more than refraining from harming-often it calls for active interference. The principle of beneficence presents a complication as there apparently is no restriction or limitation to the extent of our obligation to produce good.

Care as a normative value is indeed related to the ideal of not inflicting harm, but it must also include a reasonably limited commitment to actively working for the prevention of harm. Furthermore, the normative value of care is related to the ideal of contributing to the promotion of good, but it must be narrowed down in order to not entail self-sacrifice or the sacrificing of the well-being of a third part. Care, the normative core of the ethics of care, can be portrayed as a merging of the principle of non-maleficence when it is expanded to allow for certain types of interventions, and the principle of beneficence when it is restricted to the prevention of systematic self-sacrifice and the surrendering of the concrete others' interests [23, pp. 40-46].

Different ethical theories have different normative core values. The ethics of care highlights care; deontology accentuates rights; the theories of justice emphasize justice; and the utilitarian tradition values the society's overall well-being. In addition to its unique normative core value, the ethics of care is distinguished even further from the above mentioned theories by its distinct moral ontology and moral epistemology. Actually, the deontological, utilitarian and liberal traditions have a relatively shared ontological and epistemological foundation. Regarding the

\footnotetext{
${ }^{3}$ The ethics of care address harm not only within categories such as private, social and global, but across them.
} 
ontology of the ethics of care, as previously explained, the moral agents are envisioned as related, interconnected, mutually dependent, and often unequal in power and resources - as opposed to the conventional portrayal of the agent as independent, equal and self-sufficient. With regard to the moral epistemology, the ethics of care relies not merely on deduction and abstract reasoning, rational calculations or rule following. The moral epistemology of care includes taking experiences into account, exercising self-reflections and sensitive judgments where contextual differences are attended to [3, 23, p. 81]. These aspects of the ethics of care's philosophical foundation bestow the ethics of care with some similarities both to communitarianism and virtue ethics. All three theories are concerned with experience, judgments and humans' embeddedness in relations. Some of what distinguishes the ethics of care from these two traditions is its strong focus on experiences and relationships traditionally associated with women and their care work. Hence, care ethicists have scrutinized a largely unexplored domain within moral philosophy. Furthermore, a feminist ethics of care does not immediately value experiences and traditions as good, or normatively defensible, as typically done within virtue ethics and communitarianism. A feminist ethics of care is not conventional; it does not conserve the status quo-as tended by the two latter theories in question. On the contrary, care ethicists are well aware that care often takes place under oppressive conditions [7, 15, 17, 18, 29]. Identifying and discussing the practices and values that ought to be preserved, nurtured, altered or rejected is an important task of any feminist ethics.

Although this discussion does not give an exhaustive portrayal of the normative features of the ethics of care, nor of its differences and similarities with other ethical theories, it is hopefully sufficient to explain why the application of an alternative normative perspective will allow variable readings of empirical situations and ethical challenges. This also indicates that no single ethical theory is all-inclusive, and illuminates why it is often necessary and beneficial to review ethical challenges from several normative perspectives before drawing conclusions, making decisions or passing judgment.

\section{Comprehending Care as Mature Care}

The relational ontology, where moral agents are envisaged as entrenched in a web of relationships, could also be conveyed into our idea of care. When including the relational and reciprocal mode of thinking as part of our idea of care, it paves the way for a novel understanding of what it means to care-on the theoretical as well as on the practical level. This expanded idea of care exposes caring to be a relational process in which both the carer and caree participate. To prevent inflicting harm and/or to promote flourishing, these aims of caring must hold true for both the carer and the caree. Several care ethicists have drawn attention to the fact that the interests of the one-caring must also be attended to [5, 7, 17]. This amplification is actually derived from the fact that the normative value of care is universal-it includes not only the caree, but also the carer and other persons for whom she might have a caring responsibility. On a general level, this means that the interests of not 
being harmed and being able to flourish should count equally for all relevant parties. This particular comprehension of care is what I term the concept of mature care. The concept of mature care recognizes that, in principle, one should have as much care for oneself as one has for others $[21,23]{ }^{4}$

The term mature care was mentioned by Carol Gilligan in her seminal book In a Different Voice (1982) [7], when she characterized those of her informants who were able to weigh and mediate the interests of both self and others. This is an important, relational way of comprehending care, where the interests are given equal consideration. In addition, the term mature care can denote affinity with Aristotle, more precisely with his theory on the golden mean: The moral agent search for a mean between too little and too much care for self and others. Also, the term mature care shows that the effort to reach a state of mutual recognition is the result of a certain manner of growth. Maturity is obviously the obverse of immaturity, and by incorporating both terms, I also mean to integrate some epistemological points. The idea of maturity and immaturity challenges the sharp distinction between reason and emotion, or rather those mature enough to manage the balance between reason and emotion, and those who accentuate emotion or reason at the expense of the other [16]. ${ }^{5}$ It demonstrates that the cognitive capacities needed are acquired through a development, that neither reason nor emotions ought to be excluded, and that they can be present in various degrees.

Also the relational ontology plays a prominent part in the understanding of care as mature care. It is certainly possible to understand care as the prevention of harm and the encouragement of flourishing also on the basis of an individualistic ontology. But if so, the relational and reciprocal aspects of care disappear-at the risk of having few, if any, restrictions on how much good to produce for others, or to what extremes a carer should go in order to prevent others from being harmed. A comprehension of care based on an individualistic ontology tends to view care as a mono-directional activity, something which is transferred or given from the carer to the one cared for. As a consequence, the interests of the carer (and possibly the third party) can be severely neglected. This understanding of care can be termed an altruistic understanding of care, and it consists of a cluster of elements used to comprehend and evaluate the practice of caring — such as care being understood as a selfless act that is provided compassionately and unconditionally to a particular needy human being [14, 23-25].

Understanding care as mature care reveals why care does not enamor asceticism and self-denial, or a pure altruistic approach to the needs of others. It would be misconceived and evidence of a misunderstanding of what it means to care were we to equate care with self-sacrifice or self-denial on the one hand, ${ }^{6}$ or, with a narrowly

\footnotetext{
${ }^{4}$ There are, of course, practical challenges related to this because in a caring relationship one part is often more dependent than the other, but within the limits of this article, these challenges cannot be addressed.

${ }^{5}$ Deriving the concept of mature care from Aristotle is not however, to say that the ethics of care is a (version of) virtue ethic.

${ }^{6}$ Boundless care as an ethical requirement is loaded with problems-both theoretical and practical. On the theoretical level, it is difficult to argue why the interest of one person, group or nation should take precedence over others. In practice it is likely to curtail autonomy and freedom, be discriminatory both
} 
particularistic and self-centered concern on the other hand. Both perspectives would be one-sided, without reciprocity or mutual recognition. ${ }^{7}$ Care, understood as mature care, seeks a path between caring too little and caring too much both for oneself and for others [22, 23]. Neither my own interest, nor the interests of others should serve as a general directive-but rather a template for acknowledging the interests of all affected. ${ }^{8}$ Analogous with the conceptualization of the moral agent as related, this concept of care extends beyond intimate and private relationships, to human interaction in general.

\section{Care Epistemology and Empirical Implications}

The concept of mature care implies recognition of the interests of both self and other-an idea not to be conflated with a simple truism. It is meant to signify a perception of self and others from beyond the slave-master duo as put forth by G.W.F. Hegel. According to Hegel, the strive for recognition-in particular as a person with dignity and worth-is what separates humans from animals, and this wish is strong enough to generate a life-and-death-like battle between consciousnesses. Out of this struggle the slave-master relationship emerges. The hostility and lack of recognition can be understood as alienation [10, pp. 119-121]. When the interests of self and others are acknowledged, as they are by practitioners of mature care, people recognize each other as persons entitled to care and consideration, over and above whatever differences or hostilities may divide them. This epistemic position impinges on the agent's comprehension of herself, on the cared-for and on this particular understanding of human interaction. Not only does an epistemological transformation of this caliber affect moral philosophy and epistemology [23, pp. 65-84]. It has practical consequences as well, providing the agent with an ability to perceive the situation differently, to approach and solve conflicts in alternative ways. How is this possible? It is because of the epistemic implications of mutual recognition that are inherent to this particular concept of care. Therefore, we shall proceed to inspect the effect recognizing the interests of both ourselves and others has on our moral outlook, both those who care too much, either for themselves or for particular groups or causes, and those who care too little.

\footnotetext{
Footnote 6 continued

with regard to the one caring and the one cared for, and it will also promote paternalism, self-sacrifice and exploitation. I explore these difficulties more thoroughly in "Conceptions of Care: Altruism, Feminism and Mature care", forthcoming in Hypatia. A Journal of Feminist Philosophy.

7 The battered wife who cares too much for her partner, and too little for herself, puts up with the abuse. The terrorist cares too much for a cause and too little for the victims, a nation is often too much concerned for its own people and too little for those of others.

8 Indeed, balancing the interests of self and other in concrete situations throws up a host of practical challenges. I cannot discuss them here, but mere mention how the idea of mature care has epistemic implications with regard to how one perceives and approaches conflicts. My main concern in this article is with the philosophical tools made available to us by the ethics of care for approaching and overcoming practical challenges.
} 


\section{Care and Self-Centeredness}

A narrow or exaggerated concern for oneself, or a particular group, is often the cause of dispute and even violence. A care ethicist would approach, or intervene in, conflicts of interest not by assaying the agents' rights under some moral, legal or religious principles, but by appealing to their capacity to care. But why should a self-centered agent bother with a call for mutual care and promptly recognize the other party, one may ask. There are at least two reasons which make this transformation plausible. First, care ethicists aspire to activate a common experience. Hostile attitudes toward others and abusive behavior do not necessarily prevent a person from showing care and compassion (or vice versa for that matter) in other situations. A person who behaves aggressively in one situation may be an outstanding caregiver in another, and will almost certainly have been cared for by others. What impels people to change from narrow self-centeredness to caring for the well-being of others is because the experience and knowledge of care are virtually universal: everyone knows what care feels like, on the receiving end, and as a giver of care. The values and tenets on which care is based are not limited to private subjective emotions and sentiments, nor are they grounded in religion, culture, academic qualifications or class. They are a shared human experience. Due to its origin in common experience, the values of care can be understood as easily by the perpetrators of violence, the inconsiderate bureaucrats, as by politicians and leaders. Therefore, the process of transforming antagonistic or abusive relationships into tolerant and non-abusive relationships can start by reviving the values and knowledge of care in the self-absorbed agents.

The second reason why an appeal to mature care might widen a self-centered focus is that it is rational. The question here is how one can argue consistently to claim or wish something for oneself, but deny and deprive others of the right or opportunity to do likewise. Most rational agents seek to avoid contradicting what appears to be self-evident. Or, in the words of Hannah Arendt, "If you are at odds with yourself it is as though you were forced to live and have daily intercourse with your own enemy. No one can want that." [1, p. 91] By recalling the experience of care, the agent also recognizes the significance of care to other people. The importance of care and concern does not decline simply because the other is poor, powerless, lives far away or belongs to another religion, race or nation [4]. Nor is it related to their level of rationality or education. By recognizing others as humans in need of care, one undermines perceptions of the other as an unfamiliar alien, investing them instead with individuality and humanity and discovering similarities between oneself and the other. By appealing to care, we encourage the act of identification and sometimes empathy. Robin May Scott, in her discussion of rape, tells the story of young women, interned and about to be raped. The victim asked her captor if he had a sister, something he confirmed. "How do you think your sister would have felt if someone did to her, what you are about to do with me?" she asked. The man let her go, and made no attempt to assault her again [28, p. 127]. The shared knowledge of care, can make people exchange narrow self-interest, with concern for the well-being and care of others. 
True, some people seem to feel nothing, or only resentment towards others. The inability to empathize or identify with others is regarded as a pathological disorder by some, and if it is not, Nel Noddings for one thinks it should. "Re-education or exile" is her recommended response [19, p. 92]. Bernard Williams [30] believes the problem with most callous behavior is not the person's lack of ability to care, as most do care about some others, for example their mother or their brother. The problem is that their sense of care is not extended to the wider community. The remedy, Williams suggests, is to appeal to their confined sympathies, to broaden their capacity for "other-concern". According to Noddings, broadening our ability to feel with others is the goal of (moral) education [23, pp. 62-63]. However, drawing attention to how care reasoning has a potential for resolving conflicts, should not be conflated with revealing a naïve attitude where one is taken to believe that appealing to people's empathy or their reason always could prevent individual evil, or deal with complex and violent conflicts on the global level. The point is that a variety of approaches are needed as situations are different, and that the ethics of care holds a potential for several ways to approach empirical challenges-also conflicts of interests. Appealing to rational identification and empathy are two possibilities; dialogues, imaginations and re-conceptualizations are other strategies available when applying an ethics of care. After all, the ethics of care originated in women's care work, including maternal work, arenas that are rifled with conflicts in need of being immediately handled. Feminist care ethicists do not sentimentalize care work. On the contrary, they scrutinize the abuse, violence and exploitations that might follow, and discuss what lessons can be drawn. Care ethicists are not typically pacifists; they admit that sometimes violence is necessary [11, 20, 27, pp. 152-154].

\section{Care and Other-Concern}

Mature care not only indicates a shift from self-centeredness to the recognition of the interests of others, it requires the self-denying agent to also consider her own interests and needs by balancing the interests of self and others. Pure altruism, strong devotion and self-denial, has often been associated with care, and throughout history praised as a female virtue [2, 15, 29]. But altruism in its extreme form is highly problematic (practically, theoretically as well as ethically). It is, for example, likely that pure altruistic care undermines the autonomy, integrity and growth of both the carer and the cared-for [17, pp. 49-50, 15, pp. 90-91, 12, pp. 135-138, 21, 23, pp. 123-127, 14].

At the theoretical level, favoring others at one's own expense is not consistently defendable. Actually, it is a way of surrendering one's freedom and responsibility, which in itself is ethically dubious. The concept of mature care, however, requires us to take responsibility for ourselves, something it shares to an extent with existentialist ethics as put forth by Simone de Beauvoir in her Ethics of Ambiguity (1946). Devotion and strong other-regarding care can be portrayed as a denial of our responsibility for our own life and needs. It can be understood as a rejection of the existential challenge posed by our freedom to establish our own way of life. Dedicating oneself to others can be a way of dehumanizing oneself. Or, if we prefer 
the words of Immanuel Kant, the self-denying person is reduced, or reduces herself, to a pure means. When a mature carer assumes responsibility for her own situation, and does not subject herself to the desires, will, and power of others, she is also taking ethical responsibility for her own existence and actions. Submitting oneself to the will and desires of another, might indeed help one avoid conflicts, but it will probably also diminish one as a person and reinforce the risk of becoming an instrument of others. Sometimes the devoted carer is exploited and injured, and sometimes she inflicts harm on others in the name of care.

Integrating the relational aspect to our idea of the moral agent and our understanding of care, allows us to acknowledge the significance of care in most relationships. When practicing care, there are of course situations where the carer cares for a limited number of people. Care can take many forms and intensities. But the concept of mature care acknowledges everyone-individuals and groups, near and far-as potential recipients of care. Under this concept of care there is no inbuilt particularity. The value of care is not discriminatory, nor reserved for certain categories. But nor are there prescribed detailed rules about how care should be parceled out in the event of a conflict of interest. The agent is allowed to use her own judgment, and, based on the idea of mature care, weigh different considerations. Allowing for flexibility and judgment is nevertheless not the same as random and unsystematic decision-making. The ideal of care serves as a guide to the values we should promote. When it comes to difficult choices, both Nel Noddings [19] and Robert Goodin [9] have useful guidelines: Decisions about care delivery should be made on basis of vulnerability, not on sentiment, particularism, or on biased preferences.

\section{Care Theory and Practice}

Lending support to the ideals, values and concepts developed in the ethics of care has political implications. Ethics is about behavior and conduct, and a moral agent is not only situated in her own private sphere. She is also a citizen, a professional, she is a participant in the society's wider economy. A carer is aware of the asymmetry of relationships, and acts accordingly. As a professional or a citizen, a carer could comply with professional codes and legal regulations, but she could also speak up when norms of care are violated and resist the practice of uncaring and harmful regulations and schemes. Obedience and servility are not parts of care ethics, and a carer does not justify the harsh and uncaring priorities, for instance in health care. A carer will also rule out political views and actions that withhold or curtail care, and encourage actions likely to promote care and human flourishing. Abuse by a mother or nurse is clearly in violation of the ethics of care, as is fighting against aiding victims of war or alleviating world poverty. Actions, on all levels, have this dual propensity, to violate and strengthen the values of care.

Care ethicists have the values, perspective and the analytical tools to identify actions and conducts which are promoting-or curtailing-care. But at the same time this normative theory is also disposed toward ignoring the social structures, or the big scheme of things, where the singular uncaring actions subsume. As the ethics 
of care focuses on the concrete, unique and singular, it detects harm easily overlooked from other perspectives. Concentrating on the concrete other can nevertheless make it difficult to see the structures and pattern common to the individual cases and concrete conflicts. Political actions for care ethicists do not necessarily, or indeed not only, consist in bringing anecdotes, or the singular, into political debates. Based on the knowledge of particular cases, the care ethicist must also work to identify uncaring arrangements and structures. Failing to see the larger framework of uncaring action, or merely treating it as one of its kind, might conceal uncaring and harmful structures and the abuse of power [17, 29]. The epistemic significance of altering between different perspectives is at play here also; when the mature carer faces empirical challenges and shifts between the concrete and singular, and the abstract and universal perspective, new ways of handling empirical challenges might also be revealed.

Care philosophers concerned about developing this ethical theory pay attention to the interface between the normative and the empirical, between philosophy and practice. The approach is to scrutinize real life experience, and use this knowledge as a basis for developing analytical concepts and theories in order to better understand and handle what one empirically faces up to. In fact, the ethics of care grew from work to remedy a certain narrowness of view in philosophy, to extract from the practical experience of care by real people a normative concept of care [7, $19,27]$. The ethics of care is not confined to abstract speculation about values, or to collecting idiosyncratic experiences. It reasons neither from the top-down, nor from the bottom-up. Its theory is founded in an ongoing dialogue between the normative and the empirical. Consequently, the ethics of care acknowledges the interplay of context and value: situated people create situated values. To deny or disguise the contextual origin of norms encourages false generalizations. Values and norms from one context can nevertheless be relocated in other contexts. What the moral philosopher can do is to analyze and articulate value systems, draw attention to problems and possibilities, and supply well-founded justification when necessary. She can highlight likely contradictions and consequences of acting on these values. This is exactly what care philosophers do as they expand the domain of care ethics from the private to the collective and global levels, when they scrutinize the interface between normative theories and empirical challenges.

\section{Political Implications}

As I have emphasized, care can be present in all types of relationships, and I shall end by emphasizing that so may conflicts, hostility and violence. Conflicts can flare up between individuals and within families, as much as between groups and states. There is a particular relationship or balance between hostility and care, between violence and caring. Hostility and violence are the flip side of caring. A violent or harmful relationship, be it private, public or global, between individuals or between individuals and institutions, signifies a lack or absence of caring. Violence violates the values on which the practice of care rests. Violence negates trust, compassion and attentiveness; it disregards basic human needs and stunts growth. Mutual 
recognition, the hallmark of a mature caring relationship, is replaced by alienation. Violent relations deprive people of their individuality; they are seen only in terms of wickedness, culpability or risk [28, p. 127]. Hostility can be sustained only by depersonalizing one's opponent, by casting suspicion on their motives and imputing a stereotypical, rigid mindset. Epistemologically, hostile relations widen dichotomies_-I/thou, good/evil, right/wrong, friend/enemy. The thoughts, feelings and attitudes of the other are suspended, reciprocity broken. A violent relationship is non-discursive; reciprocity through communication, dialog and exchange is essential in a caring relationship.

People in a caring relationship do not, ideally speaking, dichotomize, they perceive in terms of relatedness. They are concerned to strengthening mutual bonds, understanding the other's vulnerability and dependency, and realizing that what might seem good and right or evil and wrong to one, might look differently to the other. In a caring relationship, particularity and individuality are essential; it is the actual, not the universal other one faces. The concept of mature care does not dichotomize, but encourage one to think and perceive in terms of relatedness. Reciprocity through communication, dialog, exchange of opinions, listening and the willingness to see the situation within the perspective of the other are essential from the idea of mature care. An approach to conflicts based on the idea of mature care would therefore involve encouraging agents to see situations from the other's perspective. An ability to shift perspective is part of the wider epistemological capacity to care. As a contribution to moral theory, requiring agents to approach situations from different directions challenges accepted ideas of what passes for knowledge in moral decision-making, while offering a new method and new type of knowledge: the knowledge of care.

Again, we see how the reciprocity and mutual recognition inherent in the concept of mature care can widen our appreciation of empirical challenges represented by conflicts, and give us other ways of addressing them. This capacity is one of the epistemological implications of integrating relatedness into our conception of mature care. The empirical result of such thinking might be that we universalize the value of care, and in doing so we include our self as well as any out-group. The sensitivity of care ethics to inequality and the interconnectedness of moral agents, its more expansive understanding of moral epistemology and the moral domain, and the relational aspect within the idea of mature care, are some of the conceptual ways of doing moral philosophy that care philosophers can bring, not only to the development of moral theory, but also to difficult empirical challenges. When the ethics of care addresses a new arena, its relational ontology can identify asymmetric relationships within and across domains-situations calling for analysis in terms of care. In order to achieve this, we need contextual knowledge, insight into the norms of caring, conversing with the other-and putting oneself in their place. Care ethicists would, for instance, argue that if the values and conceptualizations of the ethics of care were incorporated in political deliberation and decision-making, and in the assessment and drafting of social schemes and international agreements, conflicts and hostility, political and structural violence could decline. If care, as a value, were as prominent in political thinking as rights, justice and freedom, some harmful conflicts could be prevented, insofar as conflicts and violence are 
symptomatic of non-caring relationships and communities. A care ethicist would not be satisfied knowing only whether others enjoy rights and freedom. She wants to explore the totality of the relations-for instance by working to eradicate the causes of harm and organizing the daily lives of professions, society and the international community in ways that ensure and encourage caring relationships. Some might consider this to be wishful or naïve thinking on the part of care ethicists. However, if hope and vision for a better future do not exist, and if faith in the possibility to change ordinary lives is not present, a normative theory is certainly defective. Theories are indeed not all that is required for facilitating real life changes. Still, the contributions rendered by enhancing and disseminating novel ideas and knowledge that has grown from seeds found in private caring relationships, to a now mature normative ideal that can ultimately guide human interaction, is indeed a highly significant one.

Acknowledgments I am grateful to the Department of Philosophy, Classics, History of Art \& Ideas, University of Oslo for granting me the flexibility I needed in order to complete this article. Also, I would like to thank Chris Saunders and Joseph Thraen for assisting me with the proofs.

Open Access This article is distributed under the terms of the Creative Commons Attribution Noncommercial License which permits any noncommercial use, distribution, and reproduction in any medium, provided the original author(s) and source are credited.

\section{References}

1. Arendt, H. (2003). Responsibility and judgment. New York: Schocken Books.

2. de Beauvoir, S. (2000). Det annet kjønn (The second sex). Oslo: Pax Forlag A/S.

3. Dalmiya, V. (2002). Why should a knower care? Hypatia, 17(1), 34-51.

4. Cornell, D. (2005). Feminism, Utopianism, and the role of ideal in political philosophy. In E. Cudd \& R. O. Andersen (Eds.), A feminist theory. A philosophical anthology. Oxford: Blackwell Publishing.

5. Engster, D. (2007). The heart of justice. Care ethics and political theory. Oxford: Oxford University Press.

6. Galtung, J. (1974). Fred, vold og imperialisme. Oslo: Dreyer.

7. Gilligan, C. (1982). In a different voice. Psycological theory and women's development (33rd ed.). Cambridge: Harvard University Press.

8. Gilligan, C. (1988). In J. V. Ward, J. T. McLean, \& W. B. Bardige (Eds.). Mapping the moral domain. Massachusetts: Harvard University Press.

9. Goodin, R. (1988). Protecting the vulnerable. A reanalysis of our social responsibilities. Chicago: The University of Chicago Press.

10. Hegel, G. W. F. (1999). Andens fenomenologi. Oslo: Pax Forlag.

11. Held, V. (1993). Feminist morality: Transforming culture, society, and politics. Chicago: University Press of Chicago.

12. Held, V. (2006). The ethics of care. Personal, political, and global. New York: Oxford University Press.

13. Held, V. (2008). How terrorism is wrong: Morality and political violence. New York: Oxford University Press.

14. Hem, M. H. (2008). Mature care? An empirical study of interaction between psychotic patients and psychiatric nurses. Doctoral thesis, University of Oslo. http://www.duo.uio.no/publ/sykepleie/2008/ 70654/608_Hem_17x24.pdf.

15. Hoagland, S. L. (1989). Lesbian ethics. Toward new value. Palo Alto, CA: Institute of Lesbian Studies.

16. Hursthouse, R. (1999). On virtue ethics. Oxford: Oxford University Press. 
17. Kittay Feder, E. (1999). Love's labor. Essay on women, equality, and dependency. New York, London: Routledge.

18. Narayan, U. (1995). Colonialism and its others: Considerations on rights and care discourse. Hypatia, $10(2), 133-140$.

19. Noddings, N. (1982). Caring: a feminine approach to ethics and moral education. Berkeley: University of California Press.

20. Nodding, N. (1989). Women and evil. Berkeley: University of California Press.

21. Pettersen, T. (2004). Comprehending care. Problems and possibilities in Carol Gilligan's ethics of care. Doctoral thesis, University of Oslo: Unipub.

22. Pettersen, T. (2006). Omsorg som etisk teori (Care as ethical theory). Norsk filosofisk tidsskrift (The Norwegian Journal of Philosophy), 41(2), 151-163.

23. Pettersen, T. (2008). Comprehending care. Problems and possibilities in the ethics of care. Landham, MD: Rowman \& Littlefield Publishers. http://www.lexingtonbooks.com/Catalog/SingleBook.shtml? command $=$ search \&db=\%5EDB/CATALOG.db\&eqSKUdata $=0739126156$.

24. Pettersen, T. (2011). Conceptions of care. Altruism, feminism and mature care. Forthcoming in Hypatia. A Journal of Feminist Philosophy.

25. Pettersen, T., \& og Hem, M. H. (2011). Mature care and reciprocity: Two cases from acute psychiatry. Forthcoming in Nursing Ethics.

26. Robinson, F. (2006). Ethical globalization? States, corporations and the ethics of care. In M. Hammington \& D. C. Miller (Eds.), Socializing care: Feminist ethics and public issues. Landham, MD: Rowman \& Littlefield Publishers.

27. Ruddich, S. (1986). Maternal thinking: Toward a politics of peace. Boston: Beacon Press.

28. Schott, R. M. (2004). Feministisk filosofi. En introduktion. (Feminist Philosophy. An Introduction). København: Gyldendal.

29. Tronto, J. (1993). Moral boundaries. A political argument for an ethics of care. New York: Routledge.

30. Williams, B. (1972). The amoralist. In Morality: An introduction to ethics. Cambridge: Cambridge University Press. 